\title{
OS EDUCADORES AMBIENTAIS MUNICIPAIS DIANTE DA CRISE DE PANDEMIA ${ }^{1}$
}

\author{
Wanderleia Aparecida Coelho² \\ Maria Arlete Rosa ${ }^{3}$ \\ Samira Kauchakje ${ }^{4}$
}

Resumo: A percepção dos educadores ambientais diante da crise de pandemia do coranavirus em municípios da Região Metropolitana de Curitiba é aqui tratado. Busca-se relatar suas experiências em novas relações de trabalho e isolamento social. Brum (2020) e Latour (2020) tratam das inquietações com relação a expectativa de mudanças positivas pós-pandemia. Alertam para o risco que voltemos como era antes e marcados pelas sequelas geradas nesta crise. Constatou-se em estudo com estes educadores ambientais que os mesmos compreendem o contexto de pandemia pela realidade vivida, de suspensão de suas atividades. Reconhecem a Educação Ambiental como essencial para entendimento e enfrentamento deste momento e de novos que venham a surgir.

Palavras chave: Pandemia; Saúde Pública; Educação Ambiental.

\footnotetext{
1 Destaca-se que este relato de experiência faz parte do Projeto de Pesquisa das autoras, tendo como primeira etapa deste estudo a Revisão Sistemática de Literatura sobre a relação entre pandemia e o ambiente em fase de desenvolvimento. $O$ relato dos educadores ambientais que atuam na gestão ambiental de municípios da Região Metropolitana de Curitiba e que participam do Grupo de Trabalho de Educação Ambiental vinculado ao Ministério Público do Paraná, coordenado pelo Centro de Apoio Operacional das Promotorias de Proteção ao Meio Ambiente e de Habitação e Urbanismo, constitui-se como uma ação inovadora no âmbito do Ministério Público e será campo de pesquisa a ser articulado aos resultados gerados por esta revisão de literatura para fundamentar a análise dos depoimentos dos entrevistados.

2 Companhia de Saneamento do Paraná, Sanepar, Assessoria de Educação Ambiental no Ministério Público do Paraná. E-mail: wacoelho@mppr.mp.br

3 Universidade Tuiuti do Paraná. E-mail: mariaarleterosa@gmail.co

4 Universidade do Estado de Santa Catarina. E-mail: kauchakje@gmail.com
} 
Abstract: The perception of environmental educators in the face of the pandemic coronavirus crisis in municipalities in the Metropolitan Region of Curitiba is addressed here. We seek to report their experiences in new work relationships and social isolation. Brum (2020) and Latour (2020) address concerns about the expectation of positive changes after the pandemic. They alert us to the risk that we will return as it was before and marked by the consequences caused by this crisis. It was found in a study with these environmental educators that they understand the context of a pandemic due to the reality they experienced, the suspension of their activities. They recognize Environmental Education as essential for understanding and coping with this moment and new ones that may arise

Keywords: Pandemic; Public Health; Environmental Education.

\section{Introdução}

Este artigo apresenta a percepção dos educadores ambientais diante da crise de pandemia em municípios da Região Metropolitana de Curitiba. Buscase nos relatos das experiências vividas por esses educadores ambientais evidenciar suas percepções diante dos impactos gerados pela pandemia do COVID-19 que impôs novas condições humanas no contexto das relações de trabalho e de isolamento social. A questão colocada para reflexão pelos editores desta revista busca responder: Como construir Sociedades Sustentáveis frente à crise climática e de saúde mundial? Orienta essa reflexão a abordagem da escritora e jornalista Eliane Brum (2020) e pesquisador Bruno Latour (2020) como as referências principais indicadas pelos editores que destacam na chamada desta Edição, Brum(2020) afirma que:

O Brasil tem dois enfrentamentos urgentes para fazer: a disputa do presente, que é o novo coronavírus, e a disputa do futuro, que se dá também agora, no presente. Parece impossível disputar o futuro nessas condições. Mas tudo o que temos é encontrar um caminho para minar a criatura chamada capitalismo, que no nosso tempo se expressa pelo neoliberalismo, e impedir que se regenere. Mais do que nunca, hoje lutamos pela vida.

Participar da Edição Especial desta a Revista, atribuindo protagonismo da Educação Ambiental num contexto de luta pela vida no calor da hora em que a pandemia é o grande desafio como questão global no sentido de garantir a vida de milhares de pessoas no planeta, representa um esforço para sair do isolamento social e se debruçar sobre a reflexão na busca pela construção de pontes futuras de sustentabilidade. Esta Edição Especial sobre os "Educadores Ambientais frente à crise de uma pandemia: qual futuro queremos e como construí-lo com justiça social e ambiental" neste momento de isolamento social contribui para uma tomada de posições pessoais e coletivas no campo de 
atuação profissional, social e espiritual. É nesta perspectiva que se busca trazer os relatos das experiências de educadores ambientais que estão na linha de frente da área ambiental nos municípios que integram a Região Metropolitana de Curitiba. Proporcionar esta autoreflexão representa um momento de formação de sujeitos ativos de seu próprio processo histórico. Assim, foram realizadas entrevistas com oito integrantes do Grupo de Trabalho de Educação Ambiental (GTEA) coordenado pelo Centro de Apoio Operacional das Promotorias de Proteção ao Meio Ambiente e de Habitação e Urbanismo, do Ministério Público do Paraná. Assim, a tarefa central trata-se de reunir elementos para refletir visando contribuir com práticas que resultem em

mudanças ambientalmente e socialmente positivas, para todas as comunidades de vida e dimensões sociais

\section{Método}

A abordagem qualitativa de pesquisa por meio da coleta de dados de entrevistas fundamenta a sistematização do relato de experiência. Com o propósito de obter as informações que viessem a contribuir para a produção do artigo, foram selecionados dez educadores ambientais com atuação na área de gestão ambiental dos municípios pesquisados e integrantes do Grupo de Trabalho de Educação Ambiental (GTEA) coordenado pelo Centro de Apoio Operacional das Promotorias de Proteção ao Meio Ambiente e de Habitação e Urbanismo, do Ministério Público do Paraná.

O Grupo de Trabalho de Educação Ambiental (GTEA) tem como objetivo, acompanhar e monitorar a implementação das Políticas Públicas de Educação Ambiental (PPEA) nos Estado e Municípios. Integram o GTEA gestores públicos estaduais e municipais das Secretárias de Meio Ambiente e Educação dos Municípios que compõe a Região Metropolitana de Curitiba (RMC). Conta ainda, com representatividades das Universidades Estaduais, Federais e Particulares, Instituto Chico Mendes de e Conservação o da Biodiversidade (ICMBio) e IBAMA (Instituto Brasileiro de Meio Ambiente).

Deste modo, os critérios adotados para a participação da pesquisa consideraram aspectos e características socioambientais que os Municípios Metropolitanos apresentam na interação com Curitiba e que por sua vez, demandam respostas integradas, articuladas e de interesse comum. Estes aspectos socioambientais configuram-se em: municípios com áreas de Mananciais, município onde está instalada a sede do Consorcio Intermunicipal para Gestão dos Resíduos Sólidos Urbanos e municípios com desenvolvimento industrial significativo.

A partir de então foram encaminhados os questionários de entrevistas, por e-mail, para dez gestores públicos das áreas de Meio Ambiente, com Educação Ambiental, para que participassem do processo. Devido à baixa adesão quanto as devolutivas das respostas do questionário, optou-se em compactar o conjunto de perguntas em três questões para realizar as entrevistas, que foram coletadas por meio de vídeo chamadas. Assim, foi 
possível contar com participação de oito entrevistados. As entrevistas foram transcritas pelas autoras. Os entrevistados serão identificados pela letra $\mathrm{P}(1,2$, $3,4,5,6,7,8)$ no sentido de manter o sigilo dos entrevistados.

A sistematização das entrevistas seguiu a ordem das três questões compactadas a partir do proposto pelo pensador francês Bruno Latour são apresentados na integra dos depoimentos dos entrevistados.

\section{Relato das experiências}

Os relatos de experiência dos Educadores Ambientais com atuação na gestão ambiental dos municípios que integram a Região Metropolitana de Curitiba e que também integram o Grupo de Trabalho de Educação Ambiental vinculado ao Ministério Público do Paraná, respondem a questão sobre "Quais as atividades agora suspensas que você gostaria que não fossem retomadas?"

P1: Nenhuma. Todas as atividades socioambientais que foram suspensas como visitas, contatos, cursos e palestras são essenciais e não devem ser suprimidas. Tem muita coisa a ser realizada em bairros carentes, nas áreas de mananciais como no Minguava e no Itaqui. E as atividades socioambientais não se mantem somente com impressos.

P2: Na perspectiva ambiental tem muita coisa que não poderia ser retomada, principalmente as que contribuem diretamente para aumentar os impactos socioambientais. Pois é sabido que a redução da mobilidade de pessoas, de veículos, modo de consumo tem refletido diretamente nas questões ambientais. Como exemplo a redução de emissões de carbono; a redução de consumo e geração de resíduos. No entanto, se contrapõe ao impacto econômico. É o grande contraponto da questão ambienta, da saúde púbica e da situação e econômica. Até porque teremos mais epidemias.

P3: na perspectiva dos serviços públicos as atividades as atividades que foram suspensas deve ser retomadas e readaptadas; e deveriam voltar a existir de modo diferente.

P4: Todas as atividades que não ditas de Educação Ambiental mas que na verdade não são deveriam deixar de serem realizadas. Por exemplo: atividades que são "chamadas de EA de paisagismo", catação de lixo em focos em terrenos baldios, mutirão de limpeza onde os trabalhadores são educadores ambientais. Estas atividades de EA estão suspensas.

Resposta coletiva de P5, P6 e P7: Não reconhecemos atividades que foram suspensas e que não deveriam ser retomadas. A questão é desenvolver o bom senso para identificar atividades que devem ser transformadas, principalmente as que interferem na vida. No âmbito das atividades que realizamos, as que envolvem as escolas, os aglomerados, os mutirões de limpeza em bairros e projetos como 0 Reflorescer em Pinhais que mobilizam muita gente. 
A seguinte questão que foi abordada pelos entrevistados tratou das atividades agora suspensas que o entrevistado gostaria que fossem retomadas ou mesmo recriadas a partir do zero. Assim, os depoimentos dos entrevistados é o que segue:

P1: As atividades socioambientais devem ser retomadas e ampliadas com muito mais estratégias on line. Estas formas de trabalho evitam e reduzem o deslocamento, a poluição. Também proporcionam mais conforto. Não substituem o contato mas contribuem para natureza se regenerar. Não vejo atividades que não deveriam ser retomadas. As atividades remotas que vieram, ficaram pelo baixo impacto. Precisam ser revistas e reduzidas para baixar o ritmo. Mas deverão ser melhoradas e mantidas.

P2: Deveríamos aproveitar para incentivar movimento como os que surgiram na Europa, por exemplo o slow food; baixar o ritmo das atividades, reduzir jornada de trabalho; redução de ritmos ou baixar o ritmo imprimindo uma velocidade baixa que também reflete sobre a produção e o consumo.

E chama atenção o que aconteceu com o aumento do consumo de alimentos, que eu acredito tem a ver com a ansiedade, o medo e a insegurança.

P3: A Educação Ambiental foi suspensa, mas, é a mais importante das atividades a ser retomada. E deverá ser retomada via virtual. E o maior impacto foi e será em todo o processo de formação. É importante aproveitar o que este momento trouxe das atividades online. E é preciso adaptar a construção de um conhecimento para que os professores tenham acesso, estímulo e que as reuniões presenciais sejam lugar de troca de experiência.

P4: Retomar as atividades de Educação Ambiental de forma mais eficaz para atingir a população com relação sua importância. A EA precisa estar mais perto da área de Comunicação, principalmente nestes tempos e tratar de temas socioambientais do município que deveriam estar nas plataformas municipais, a exemplo do que fizeram na semana de meio ambiente. A EA deve usar mais as mídias digitais.

Resposta coletiva P5, P6 e P7: As atividades de EA devem ser repensadas enquanto ser humano e no nosso trabalho. Deve se adaptar as mudanças, precisar ser adequada principalmente, em relação aos projetos desenvolvidos nas escolas. É preciso criar e implantar novos projetos. E mesmo sendo necessário o "mundo online" também é restritiva, nem todos tem acesso. E temas como a água, e as mudanças climáticas precisam ser mais trabalhados nas escolas e na vida. 
A seguinte questão a ser respondida pelos entrevistados trata de "como caminhamos para esta sociedade sustentável? O que podemos fazer"

P1: No momento, a pandemia trouxe a possibilidade de fazer uma revisão de conceitos: desacelerar, reduzir o consumo, realizar a produção mais caseira, se alimentar de modo mais saudável, fazer horta para produzir os alimentos. Fazer o que sempre dissemos; pequenas atitudes do dia a dia! Fiz composteiras, estou produzindo cosméticos naturais, reaproveitamento os alimentos. Fazer coisas junto com a família. Tempo para viver o que se diz!

P2: Educação Ambiental é o único caminho. De Educação para a cidadania, despertar a consciência para a problemática que é sistêmica. E que tudo é consequência da ação de quem se diz "homo sapiens".

Tatiane: O caminho da sociedade sustentável está nas mudanças de gestão pública e impactam que causam diretamente na população, no cidadão. Pois o consumo aumentou e gerou mais resíduos de embalagens, mais descartes na rua (colchão e sofá), eletroeletrônicos sendo jogados e as pessoas desapegando, no entanto consumindo. Em média, aumentaram a quantidade de resíduos em $15 \%$ nos aterros.

P4: Como humanidade e como educadoras, devemos recuperar a humanidade que significa: pensar no próximo, preocupar-se com as consequências dos seus atos; olhar para não jogar comida enquanto tantos passam fome, aprender a serem mais solidárias. Pois ainda não sabem ou não querem colaborar e cooperar

Resposta Coletiva P5, P6 e P7: O planeta está fazendo a seleção natural, Algumas pessoas estão começando a despertar para a questão da natureza, para a crise hídrica e mudanças climáticas. Ao mesmo tempo aumento as demanda de limpeza pública esses meses.

A Educação Ambiental tem que estar mais perto da Comunicação, nas redes de TV e nas Unidades de Saúde.

E o olhar da humanidade tem que ter empatia para poder pensar no outro. Pois a maioria ainda não pensa em si e nem no outro

As questões, que abaixo seguem, foram respondidas por escrito pela entrevistada P8 e atendeu a estrutura de perguntas inicialmente colocadas sendo a única entrevistada à responder ao questionário enviado para os dez educadores ambientais selecionados para participarem desta pesquisa. Assim, seguem as questões respondidas pela entrevista P8.

- Quais as atividades agora suspensas que você gostaria que não fossem retomadas?

P8: Com base na Educação Ambiental, que é tema central desse grupo, não vejo o verbo gostar, mas sim o termo relevância, com base do que 
nos é imposto legalmente, pressões de órgãos de controle, interesses políticos eu diria que não há atividades que não devam ser retomadas, por menor e simples que seja a ação de incentivo a Educação Ambiental, ela deve ser mantida.

- Descreva por que essas atividades Ihe parecem prejudicial/supérflua/ perigosa/sem sentido e de que forma 0 seu desaparecimento/ suspensão/substituição tornaria outras atividades que você prefere mais fáceis/pertinentes.

P8: Atividades apenas para discussão da Educação Ambiental, sem foco em objetivos claros e metas a serem alcançadas, tornam-se maçantes e sem sentido prático, a busca pelo conhecimento deve partir de cada um, indo em busca por diversos autores, não somente aqueles que lhe são simpáticos, mas também com aqueles que são oposição ao que se acredita, para enriquecimento do debate sadio, ainda mais que a Educação Ambiental é um tema muito amplo e há décadas vem sendo discutido e sua prática fica secundária, sendo aplicada de forma pontual e sem correlação com a realidade, como se fosse apenas a prática de um desejo pessoal, sem a visão de um todo.

A discussão teórica é compreensível uma vez que o país possui 27 unidades federativas, cada um com perfil distinto, cada estado composto por diversos municípios, os quais são distintos, o que justificaria a permanência da discussão teórica, afinal, às implementações de políticas públicas de Educação Ambiental, demandam de tempo, coleta de informações, análise dos dados obtidos e planejamento para definição de prioridades, metas e indicadores locais, mas para isso é necessário uso de verbas direcionadas para este fim, tais como as obtidas por fundos municipais de meio ambiente, corpo técnico capacitado e interessado, para assim obter resultados que podem fazer a diferença no futuro, afinal décadas de discussões teóricas não estão nos auxiliando a sair do ponto inicial.

Uma prática perigosa é a falta de planejamento, meta e indicadores dos serviços realizados pelas Prefeituras, o qual contribui para a falta/ausência equipamentos adequados, locais de trabalho adequados com janelas e espaço físico, respeitando as normas de acessibilidade $e$ mobilidade, veículos, mão de obra especializada e com educação escolar mínima, que não raro ocupam posição de chefia, por estarem anos a fio no serviço público, replicando erros do passado e contribuindo para a morosidade e a ausência de resultados positivos necessários, sobrecarregando funcionários. 
- Que medidas você sugere para facilitar a transição para outras atividades daqueles trabalhadores/empregados/agentes/empresários que não poderão mais continuar nas atividades que você está suprimindo?

P8:: No mundo pós pandemia, desejo universidades que desenvolvam pesquisas relevantes que facilitem o dia a dia, incorporando temas relacionados ao meio ambiente e as questões sobre Educação Ambiental, tais como consumo consciente, reaproveitamento de materiais, redução de resíduos, destinação adequada, incorporação da arborização, cisternas, uso da luz natural, luz solar, preferência por produtos que economizem energia, entre outros. Valorização do desenho universal, facilitando a mobilidade e acessibilidade, isto é, a valorização dos conhecimentos técnicos científicos, principalmente os relacionados as áreas de ciência da terra, biológicas e ciências exatas e tecnológicas.

Ver atuação da universidade nos três eixos: ensino, pesquisa e extensão de forma relevante e que atendam as necessidades das sociedades onde estão inseridas.

Desde que entrei na universidade e após anos de serviço na área, vejo que as questões sobre Educação Ambiental caminham em passos pequenos e lentos, entendo que essa dificuldade de avanços nos temas e definição de prioridades tornam-se complexos, pois vivemos em uma sociedade onde a população não sabe interpretar um texto ou fazer cálculos simples, pegamos alunos de universidades que não conseguem escrever respeitando as normas da língua portuguesa, isto faz com que fiquemos anos a fio insistindo para que a população consiga compreender a importância da separação do seu lixo e aderir no dia a dia, que consigam ver sua importância no ecossistema chamado sociedade, se ver como peça fundamental no sucesso dessa sociedade seja na esfera municipal, estadual ou federal. Infelizmente, talvez por não terem aprendido ou não querer ser vistos como responsáveis pelo local onde vivem, por não se identificar, não se sentem responsáveis pelo seu bairro, cidade, estado ou país e essas discussões de falta de identidade não são recentes, vejo essas discussões por décadas e nada evoluiu.

Com educação de qualidade, voltada ao desenvolvimento de profissionais habilitados, capacitados de forma cientifica e técnica, porque o conhecimento técnico e científico irá permitir base na tomada de decisão adequada e ética, atendendo demandas reais para a sociedade e com respeito ao meio ambiente, aos conceitos de cidades resilientes, inteligentes e sustentáveis formando profissionais capacitados para esta realidade, o mercado irá absorver esses profissionais pois iremos gerar demandas por esse tipo de tecnologia. 
Para a Educação Ambiental funcionar é necessário ir além das discussões teóricas, é se adaptar e buscar ações urgentes e práticas ao dia a dia, ser resiliente e aprender com erro passados e corrigir possíveis problemas futuros.

- Quais as atividades agora suspensas que você gostaria que fossem ampliadas/retomadas ou mesmo criadas a partir do zero?

P8: Em nosso município a trilha ecológica. $E$ iniciar o incentivo a feiras de adoção de animais e incentivo a mutirões com empresas e outras entidades como já foi realizado no passado.

Retomar a política de Educação Ambiental e inclusão da logística reversa no município, a portaria já foi realizada, mas devido a carga de trabalho e a pandemia de COVID-19 ela ficou estagnada, possivelmente adiada para 2021.

A Educação Ambiental não pode ser elaborada de forma isolada, suas ações, metas e indicadores deveriam ser cobradas nos diversos planos municipais, tais como: plano diretor, plano municipal de arborização, plano de contingências e prevenção de desastres, plano de saneamento básico, plano de gerenciamento de resíduos, plano local de habitação de interesse social, planos voltados a educação, vigilância sanitária, controle de zoonoses, saúde epidemiológica, agricultura familiar, entre outros... entrelaçando suas ações, metas e indicadores para maior sucesso na definição das atividades, coleta de dados e monitoramento.

- Descreva por que essas atividades Ihe parecem positivas e como elas tornam outras atividades que você prefere mais fáceis/harmoniosas/pertinentes e ajudam a combater aquelas que você considera desfavoráveis.

P8: A trilha ecológica foi suspensa antes mesmo da pandemia por falta de servidores para manutenção dessa atividade, no município, acredito que a trilha deveria ser ampliada porque permite uma vivência as crianças que elas não tem no dia a dia, ver a importância técnica e funcional dos parques e áreas verdes, se inserir dentro de um contexto de vivência, ver que a valeta próximo a sua casa é um rio, ver que o lixo jogado na praça pode ir até a porta da sua casa pelo vendo ou pelo rio, que a enchente é um dos sintomas da má informação, da falta de identidade com o local onde se vive, com a falta de respeito por si, pela sociedade e consequentemente pelo planeta, ao fazer a criança e professores compreender a consequência futura dos seus atos e os danos ao meio ambiente, talvez no futuro com educação de qualidade, com incentivo ao desenvolvimento de tecnologias inovadoras, com o fortalecimento e valorização do conhecimento que há décadas não vemos no país. 
A implantação de feiras de adoção de animais e mutirões diversos com empresas, outras entidades e população permitem que os envolvidos criem vivência e envolvimento na resolução de problemas comuns, adotando animais, não incentivando a produção comercial de animais de raça, criando uma rede de ações positivas entre interessados.

Os mutirões eram positivos aos participantes, porque viam reflexo das suas ações e ampliavam sua consciência sobre o lugar comum, seu papel quanto individuo no ecossistema chamado sociedade.

Para a Educação Ambiental e melhoria do planejamento municipal como um todo, vejo que a discussão e a valorização da técnica científica e principalmente das áreas de ciências exatas, biológicas, da terra e econômicas, áreas as quais vejo que estão desvalorizadas pela sociedade e gestores públicos, há décadas estão sendo sufocadas por discussões ideológicas e políticas. No futuro a imparcialidade política e ideológica deveria ser predominante, com respeito ao próximo e principalmente incentivo a leitura, ao conhecimento a valorização dos resultados técnicos e científicos, incentivo ao planejamento sustentável e de longo prazo das ações com metas claras e indicadores bem definidos, assim estaremos fortalecendo as ações que contribuem com a qualidade de vida, com proteção ao meio ambiente, usando verbas de forma inteligente e adequadas, sem cair em discussões genéricas que a há décadas acompanhamos e nada é realizado.

Um futuro onde as ações sejam realizadas, onde orgãos de controle sejam atuantes e imparciais, sem disputas de poder, e agir com real interesse ao bem estar do cidadão e bem do coletivo, há décadas observamos que todos estão em busca de projetos pessoais com à usando como desculpa o bem comum.

\section{trabalhadores/empregados/agentes/empresários/educadores a adquirir as capacidades/meios/receitas/instrumentos para retomar/desenvolver/criar estas atividades?}

P8: Fortalecimento da educação, fazer escolas onde as crianças sintam prazer em ser crianças, colégios que não pareçam pequenos presídios, sejam locais onde possam desenvolver aptidões e talentos, serem alfabetizados, não ser apenas alfabetizados de forma funcional, conseguirem desenvolver o raciocínio lógico e a criatividade em espaços adequados com hortas, jardins, energia solar, bosques, laboratórios, cisternas, uso da luz natural...

Universidades que tenham foco no desenvolvimento de profissionais capacitados com base técnica e ciência respeitando cada área, buscar formar profissionais éticos, que compreendam que o conhecimento técnico pode e deve gerar soluções adequadas e reais aos problemas 
do dia a dia e capacitados para resolução de problemas do mundo real e forma viável, ética e técnica, compreendendo a responsabilidade profissional das suas decisões.

No Brasil estamos há décadas realizando discussões teóricas sobre tudo, temas relacionados ao meio ambiente estão sendo discutidos desde os anos 60, é necessário a implantação dessas teorias, da valorização real do conhecimento técnico e científico, valorizar tecnologias sustentáveis e inteligentes, o conhecimento técnico há décadas é desvalorizado e minimizado, valorização dos profissionais que atuam de forma ética, que sofrem historicamente com a influência política, sem poderem atuar e tomar decisões com base no conhecimento técnico e científico ficando tudo ao cargo dos interesses políticos.

A Educação Ambiental precisa sair das discussões temáticas e filosóficas e ser atuante, criar metas simples, claras e objetivas, mostrar indicadores positivos sobre o resultado das ações, pois só após a apresentação de dados físicos, visíveis e comparativos será possível convencer governantes municipais, instituições de ensino, empresa, comércio e indústrias sobre sua importância e retorno positivo. Um exemplo positivo é o trabalho realizado pelo governo estadual, o qual trabalha em conjunto com o governo federal e ministério público sobre a questão da logística reversa (resíduos sólidos), trazendo resultados relevantes, interessantes e mensuráveis, atuando em harmonia e de forma coordenada com um objetivo em comum e com resolução de problemas comuns a todos os municípios valorizando o conhecimento técnico dos servidores municipais e incentivando a gestão da Educação Ambiental, pois vai além da segregação de resíduos, mas a segregação correta, reduzindo contaminações ao meio ambiente e envolvendo todos os responsáveis na cadeia, mostrando a responsabilidade de cada um. Estruturação do serviço público, investindo em pessoal habilitado e capacitado, preferencialmente com nível superior, investimento em materiais, equipamentos, veículos, fiscalização maior dos órgãos de controle para investimento dos fundos municipais em projetos e estudos.

Valorização de projetos e construções com uso de energia alternativa, aproveitamento da luz natural, respeito ao desenho universal, valorização do paisagismo, arborização, locais com lixeiras por todos os cantos.

\section{Conclusões}

O contexto e a situação em que vivemos, de pandemia como uma realidade decorrente da crise socioambiental, nos faz refletir sobre as concepções, condições e práticas de Educação Ambiental que realizamos

neste instante. Desde a década de 60, cientistas e movimentos ambientalistas 
alertam sobre as condições de vida em nosso Planeta, sobre os riscos e impactos da ação desenfreada do Ser Humano e sua concepção de que a natureza está a serviço da humanidade, que os recursos naturais são inesgotáveis e que a tecnologia encontrará saída para todos os problemas.

Desde então, o que temos é o crescente alerta sobre os problemas socioambientais e a busca de caminhos que reflitam numa nova forma de ser e estar no mundo. Portanto, a partir dos anos 70 a Educação Ambiental conquista este espaço, nas agendas internacionais, e passa a ser reconhecida como uma trajetória para o cultivo de sociedades sustentáveis. Esta trajetória percorre várias concepções atribuídas a Educação Ambiental, até a atualidade quando firma o compromisso com uma Educação Ambiental, transformadora, emancipatória, critica e reflexiva que contribua para uma nova consciência resultando num processo civilizatório centrado na vida; no respeito à todas as comunidades de vida, na dignidade humana e planetária.

Sendo assim, viver a pandemia, nos leva a refletir sobre esta trajetória, pois em poucos dias tivemos, mundialmente, mudanças profundas nas rotinas de trabalho, adoção de novos protocolos de convivência e um desacelerar dos meios produtivos e de consumo, jamais vivenciados em nossos tempos, Esta dinâmica social, resultou na suspensão, cancelamento ou recriação de atividades humanas e sociais que ainda estão em processo mas que já é sabido, refletiram em melhorias das condições ambientais. Em poucos meses a natureza se revigorou apresentando mudanças significativas na qualidade do ar, dos rios, na fauna e flora, seja aquática ou terrestre. Esta constatação coloca em evidência o quanto a ação humana agrava as condições ambientais, de saúde e convivência. Sendo que, o estilo de vida adotado na prolongada quarentena, impactam positivamente a organização dos sistemas vivos e ressaltam a necessidade da Educação Ambiental. Deste modo, a pesquisa expressa aspectos do cotidiano de quem trabalha com a Educação Ambiental, no âmbito municipal, e vive a realidade de ter as suas atividades suspensas, principalmente as que tratam diretamente com o público ou seja as atividades da Educação não formal. Este fato, interfere na compreensão e na análise dos impactos socioambientais de outras atividades suspensas e altamente nocivas para a sociedade, como um todo.

O caráter pessoal e existencial atribuído às respostas obtidas durante a entrevista revela a fragilidade dos profissionais que atuam na Educação Ambiental, a qual passa a ser analisada a partir do mesmo patamar das atividades impactantes, em seu território de atuação. Deste modo, aponta a necessidade de um processo de formação que possibilite a formação interna, como sujeitos expostos as condições de vida, e como agentes públicos compromissados com qualidade de vida de milhares de pessoas. Ainda que muito, do despertar da consciência é aplicada na rotina destes educadores. No entanto, sentem-se desafiados em buscar novas formas de acessar e sensibilizar para mudanças coletivas, por meio da Educação Ambiental, no âmbito da política pública e da mudança social, que se desejam. 
Com relação ao retorno das atividades, a pesquisa aponta para a necessidade de se trabalhar uma Educação Ambiental, mais próximas dos meios de comunicação e como estratégia de gestão. Que os temas e conteúdos precisam retratar a realidade municipal a partir do contexto global ou planetário. Temas como a Água e Mudanças Climáticas são elencados como temas primordiais por estarem diretamente relacionadas a saúde, a qualidade e existência de vida no Planeta. Esta compreensão globalizada pode ser compreendida como resultado do advento da pandemia uma vez que, planetariamente, vivemos as mesmas condições e fragilidades. No entanto de modo diferenciado, quando consideramos a qualidade da gestão pública e características socioambientais locais. De certo modo, vivenciamos a frase "Pensar Global e agir local", ainda que de modo mais difícil frente a pandemia existente.

E com relação à construção de sociedades sustentáveis, as respostas e reflexões reconhecem a Educação Ambiental como essencial para este processo de mudança. No entanto sentem-se desafiados a realizar uma nova Educação Ambiental que resulte, efetivamente, em ações propositivas capazes de promover as mudanças necessárias nas dimensões das políticas públicas, no contexto da participação social e no despertar da consciência do que é sustentabilidade.

Concluindo cabe citar o educador Pedro Jacobi, que fala de uma Educação Ambiental que promove a compreensão que "a noção de sustentabilidade implica, portanto, uma inter-relação necessária de justiça social, qualidade de vida, equilíbrio ambiental e ruptura com o atual padrão de desenvolvimento". Aspectos estes que estão com suas "feridas expostas" diante da crise de pandemia que vivenciamos planetariamente e que, atinge à todos ao evidenciar a ruptura e campo de conflito entre as dimensões sociais, ambientais e econômicas.

\section{Referências}

BRUM, E. O futuro pós-coronavírus já está em disputa. Disponível em: https://brasil.elpais.com/opiniao/2020-04-08/o-futuro-pos-coronavirus-ja-estaem-disputa.html . Acesso em: 2 Jul.2020.

\section{LATOUR, B. A crise sanitária incentiva a nos prepararmos para as mudanças climáticas. Disponível em:} http://agbcampinas.com.br/site/2020/bruno-latour-a-crise-sanitariaincentiva-a-nos-prepararmos-para-as-mudancas-climaticas/. Acesso em 3 jul. 2020.

JACOBI, P. et al. (orgs.). Educação, meio ambiente e cidadania: reflexões e experiências. São Paulo: SMA, 1998. In: LEFF, E. Epistemologia ambiental. São Paulo: Cortez, 2001.

MEADOWS, D. et al. Limites do crescimento: um relatório para o projeto Clube de Roma sobre o dilema da humanidade. São Paulo: Perspectiva, 1973. 